\title{
Renal histopathology features according to various warm ischemia times in porcine laparoscopic and open surgery model
}

\author{
Robert Sabbagh, BPharm, MSc, MD, FRCSC; ${ }^{*}$ Arun Chawla, MD; ${ }^{\dagger}$ Britton Tisdale, MD; ${ }^{\dagger}$ Kevin Kwan, MD; \\ Suman Chatterjee, MD; $;^{\dagger}$ Jacek M. Kwiecien, DVM, MSc, PhD; ${ }^{ \pm}$Anil Kapoor, MD, FRCSC ${ }^{\dagger}$
}

See related article on page 44 .

\section{Abstract}

Background: Thirty minutes has been considered as the threshold for tolerable warm ischemic time (WIT). Recent reports demonstrate recovery of renal function after longer WIT. We assessed renal histology according to different WIT in a 2-kidney porcine model. Methods: Twelve female pigs were randomized to an open or laparoscopic group. Each pig was further randomized within each group to clamping the left renal artery for 5, 15, 30, 45, 60 or 180 minutes. Preclamping left renal biopsies were performed on each pig. The contralateral kidney in each animal was used as an individual control. On postoperative day 14, all animals underwent bilateral nephrectomies. Preclamping left renal biopsies and all renal specimens were evaluated by a blinded veterinary pathologist.

Results: One pig died in the open group after 180 minutes of clamping. Histopathology did not show any significant changes between the two groups and across clamp times from 5 to 60 minutes. After 180 minutes of laparoscopic clamping, there was evidence of diffuse necrosis.

Interpretation: Sixty minutes of ischemia did not show any permanent renal damage in both groups. Further studies are needed to verify these findings in humans. A prolonged ischemic time without permanent renal damage would be helpful in partial nephrectomy. Warm ischemic time of 180 minutes exceeded the renal ischemic burden based on histological features.

Cite as: Can Urol Assoc J 2011;5(1):40-3; D01:10.5489/cuaj.10010

\section{Résumé}

Contexte : Un seuil de 30 minutes a été jugé acceptable comme durée de l'ischémie chaude. De récents rapports ont montré un rétablissement de la fonction rénale après des ischémies chaudes de plus longue durée. Nous avons évalué I'histologie rénale selon différentes durées d'ischémie chaude dans un modèle porcin à deux reins.

Méthodologie : Douze truies ont été réparties au hasard dans des groupes de chirurgie ouverte ou de chirurgie par laparoscopie. À I'intérieur de chaque groupe, les animaux ont ensuite été répartis pour subir un clampage de l'artère rénale gauche pendant 5, 15, 30, 45, 60 ou 180 minutes. Des biopsies ont été effectuées sur le rein gauche de chaque animal avant le clampage. Le rein contro- latéral servait d'organe témoin. Au jour 14 après I'opération, tous les animaux ont subi une néphrectomie bilatérale. Un pathologiste vétérinaire a ensuite évalué les biopsies prélevées sur le rein gauche avant le clampage et tous les échantillons rénaux selon un mode à l'insu.

Résultats : Une truie est décédée dans le groupe par chirurgie ouverte après le clampage de 180 minutes. Les analyses histopathologiques n'ont révélé aucune différence significative entre les deux groupes et pour les temps de clampage situés entre 5 et 60 minutes. Après un clampage de 180 minutes placé par laparoscopie, on a noté des lésions évoquant une nécrose diffuse.

Interprétation : Soixante minutes d'ischémie n'ont entraîné aucune lésion rénale permanente dans l'un ou l'autre groupe. D'autres études sont requises pour vérifier ces résultats chez l'humain. Une période prolongée $d^{\prime}$ ischémie sans lésion rénale permanente serait bénéfique dans les cas de néphrectomie partielle. Une période d'ischémie chaude de 180 minutes a excédé le fardeau ischémique rénal selon les caractéristiques notées à l'examen histopathologique.

\section{Introduction}

Traditionally, 30 minutes was defined as the threshold for renal warm ischemic time (WIT) in open surgery. ${ }^{1,2}$ However, reports show renal function recovery at WIT of 45 to 271 minutes. ${ }^{3-6}$

As advances in laparoscopic surgery continue to evolve, minimally invasive surgical techniques are being applied to increasingly complex surgical procedures. One of the limitations for laparoscopic partial nephrectomy has been the duration of renal hilar clamp time required to remove the tumour, secure hemostasis and repair the collecting system by intracorporal suturing, which may easily take more than 30 minutes.

Laparoscopic surgery has unique physiologic differences compared with open surgery. The pneumoperitoneum during laparoscopy decreases renal blood flow, resulting in relative organ ischemia that might precondition the kidney to tolerate longer WITs during laparoscopic procedures., ${ }^{7,8}$ However, prolonged pneumoperitoneum may cause decreased renal blood flow, oliguria and impaired creatinine clearance. ${ }^{9}$

Recent studies provided evidence indicating that the kidney can fully recover from WIT of up to 90 minutes in a 
single-kidney porcine model. ${ }^{10,11}$ There was no difference in renal function recovery when comparing laparoscopic and open surgery groups. ${ }^{10}$ The purpose of this study was to determine the WIT, beyond which irreversible histopathologic renal damage occurs, in laparoscopic and open surgery in a 2-kidney porcine model (normal contralateral kidney).

\section{Materials and methods}

The Animal Utilisation Protocol was approved by the Animal Research Ethics Board of McMaster University (Hamilton, Ontario, Canada). Twelve nonpregnant female pigs weighting 35 to $40 \mathrm{~kg}$ were used. All pigs were randomized into 2 groups (open vs. laparoscopic surgery) and further randomized into 6 subgroups, consisting of 5, 15, 30, 45, 60 or 180 minutes of WIT by left renal artery clamping.

In both groups, each pig underwent general anesthesia for 180 minutes. One dose of intravenous cephazolin $20 \mathrm{mg} /$ $\mathrm{kg}$ was given at induction as prophylaxis. No mannitol, furosemide, heparin, nephrotoxic drugs or renal hypothermia were used. The left kidney was completely mobilized with the renal artery and vein isolated. Before renal artery clamping, 3 biopsies with an 18 gauge tru-cut biopsy gun were taken: one from the upper, mid and lower pole of the left kidney. Samples were routinely processed for histologic studies and sections were hematoxylin-eosin-stained. The renal artery was clamped with a bulldog clamp (Aesculap, Center Valley, PA) in open surgery and with a ratcheted Laparoscopic Maryland in the laparoscopic group (Storz, Germany). In this latter group, the pigs were positioned on their right lateral decubitus and 3 ports were used. Pneumoperitoneum was maintained at $9 \mathrm{mmHg}$ during the entire procedure, which physiologically equals $15 \mathrm{mmHg}$ in a $70 \mathrm{~kg}$ human. In the open surgery group, the pigs were similarly positioned on their right lateral decubitus and a flank incision was performed. The renal hilum was easily seen by this retroperitoneal approach.

On postoperative day 14 , all animals underwent open bilateral nephrectomies under general anesthesia. The harvested kidneys were sectioned and processed for histologic study. All renal specimens (biopsies taken before clamping and kidney sections at postoperative day 14 ) were analysed by a blinded veterinary pathologist.

\section{Results}

Eleven of the 12 pigs survived. In the open surgery group, 1 pig died a few minutes after the 180 minutes of WIT (cause of death undetermined).

All preclamping biopsies of the left kidneys showed normal parenchyma in both groups as shown in 1 representative section (Fig. 1).

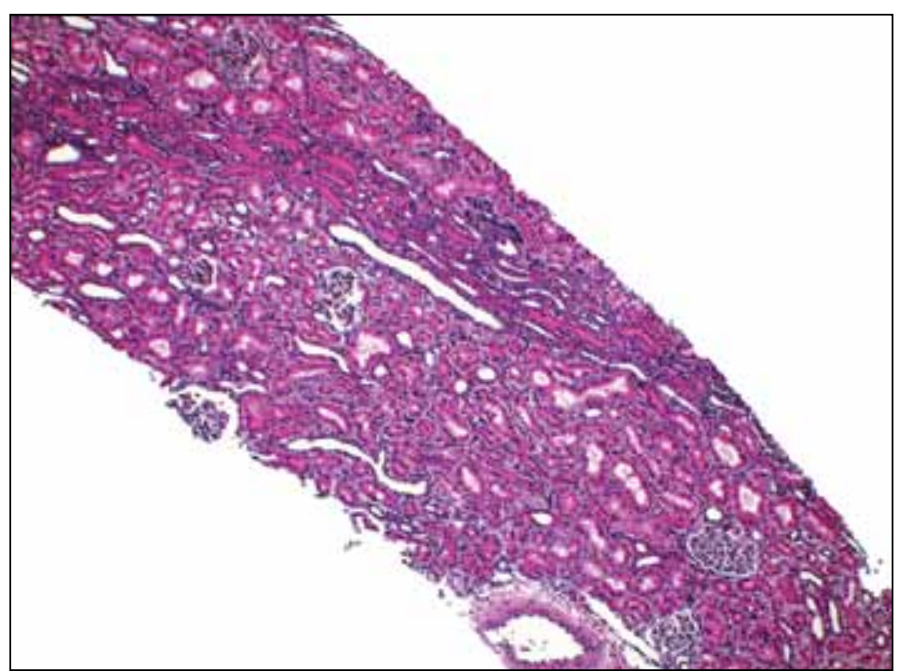

Fig. 1. Representative section of a core kidney biopsy taken before renal artery clamping. Note, normal renal parenchyma. (Hematoxylin-eosin, 5x)

Analysis of all harvested left kidneys of the 5 to 60 minutes WIT subgroups, in the laparoscopic and open groups, showed histopathology changes associated with multifocal interstitial nephritis interpreted as related to the tubular damage from ischemia (Fig.2). Most of the nephrons around those small foci of infiltration remained intact. In the laparoscopic group, after 180 minutes of clamping, there was evidence of massive and diffuse necrosis as well as infiltration, congestion and edema throughout the left kidney (Fig. 3). All contralateral kidneys harvested at postoperative day 14 were completely normal even after 180 minutes of WIT (not shown).

For the pig in the open group who died a few minutes after the 180 minutes of clamping, both kidneys were harvested immediately. The right kidney of that pig was histologically normal. The clamped kidney showed diffuse severe congestion in the intestinal blood vessels and glomerular capillary blood vessels. Tubules were lined by markedly vacuolated epithelial cells which have swollen appearance (not shown). There were no other postoperative complications.

\section{Discussion}

Historically, 30 minutes of renal WIT has been considered the upper limit for allowing complete recovery of renal function. ${ }^{1,2}$ However, tolerance to longer than 45 to 271 minutes of renal WIT has been reported in several retrospective vascular, transplant and urological clinical studies..$^{3-5,12-14}$ Other studies have reported poor renal function with such prolonged ischemia times. ${ }^{14,15}$ It would seem that kidneys with tumours amenable to partial nephrectomy may not be subjected to the same global stress as kidneys with major trauma or physiologic events surrounding the death of cadaveric kidney donors and hence may tolerate longer WIT. ${ }^{11}$ 


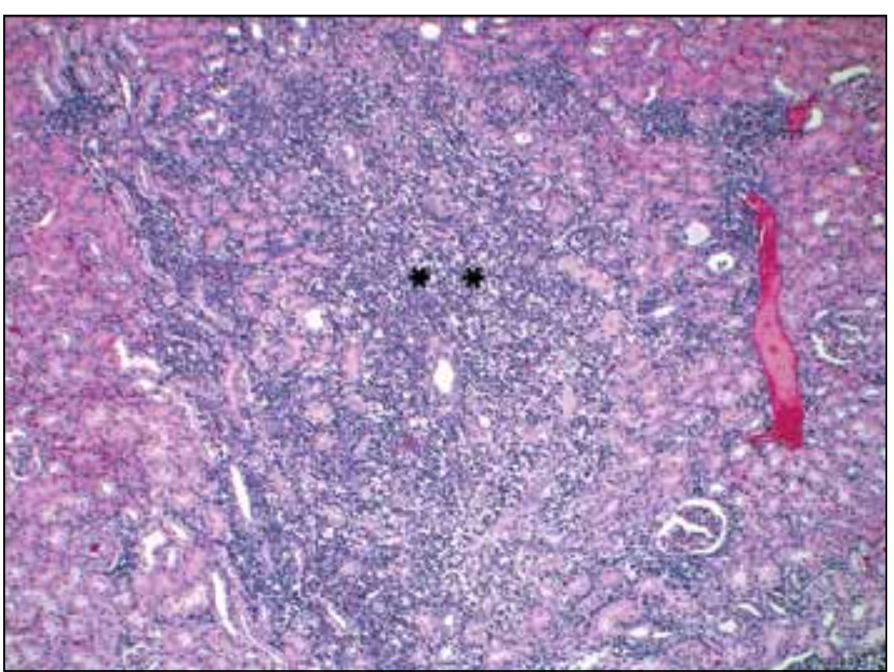

Fig. 2. Histologic analysis of a harvested left kidney at postoperative day 14 after a 5-minute renal artery clamping by laparoscopy. Note: *multifocal subacute interstitial nephritis surrounding normal parenchyma. Similar findings were obtained in left kidneys with 15 to 60 minutes clamping times in both laparoscopic and open surgery groups. (Hematoxylin-eosin; $5 x$ )

Pigs represent a good model for renal ischemia because they exhibit similar anatomy, maturation and renal function to those of humans. ${ }^{16,17}$

In our study, we clamped only the renal artery because occlusion of the entire pedicle causes more damage by avoiding oxygen consumption from the patent renal vein. ${ }^{11,18}$ In our practice, we clamp only the renal artery for open or laparoscopic partial nephrectomies.

We decided to use a 180-minute WIT to make sure that the blinded veterinary pathologist would find massive necrosis and compare these findings to the other clamping time. No scoring system was used to grade the pathology specimens due to small sample size. The small sample size is also the reason we did not report functional parameters (e.g., serum creatinine, glomerular filtration rate). However, a nuclear renal scan would have assessed split renal function in both kidneys.

Our study was ongoing prior to the publication of Orvieto and colleagues, who demonstrate that a WIT of 120 minutes produced significant renal failure and mortality in both groups (open and laparoscopy). ${ }^{6}$ However, histologic analysis of kidney specimens was not performed. In a previous study, Laven and colleagues provided evidence indicating that the kidney can fully recover from WIT of up to 90 minutes in a single-kidney porcine model in both open and laparoscopic groups. ${ }^{10}$ At postoperative day 15 , serum creatinine values and glomerular filtration rate were not significantly different from baseline at WIT up to 90 minutes. In our study, we did not evaluate 90 minutes of WIT because clinically it does not take more than an hour of WIT to perform laparoscopic tumour resection, closure of the collecting system and hemostasis.

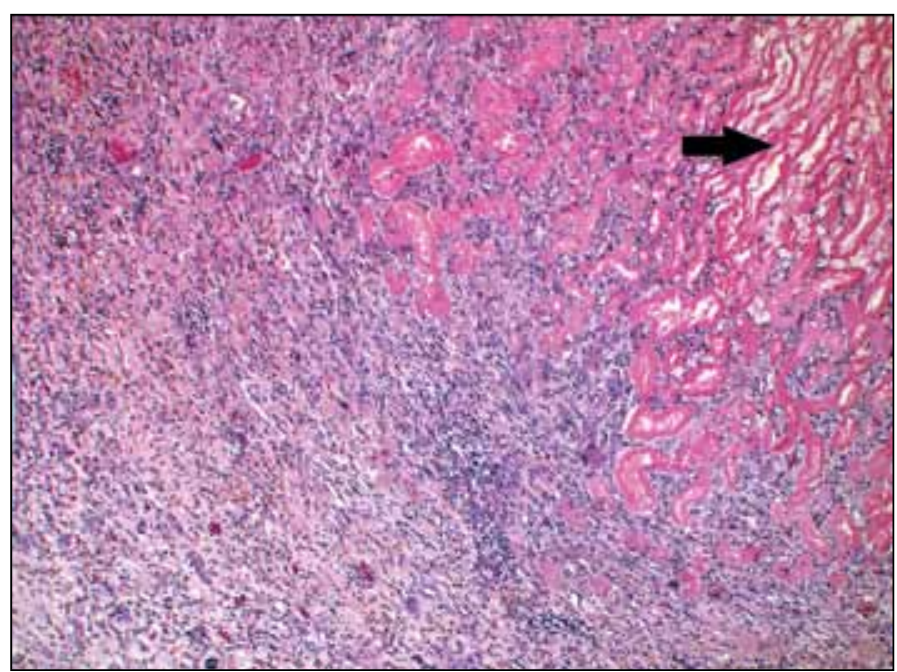

Fig. 3. Histologic section of the kidney with the laparoscopic 180-minute clamping time, harvested at postoperative day 14 days. In the cortex there are large, patchy sub-capsular areas of coagulation necrosis (arrow) with marked cellular necrosis in the interstitium and tubular epithelium in the surrounding parenchyma. (Hematoxylin-eosin; 10x)

Baldwin and colleagues studied laparoscopic warm renal ischemia in the solitary porcine kidney model by assessing renal function with serum creatinine measures as well as histologic studies. ${ }^{11}$ Serum creatinine returned to baseline by day 7 in all WIT (up to 90-minute ischemia). The authors did not evaluate kidney specimens from an open surgery group.

Recently, Humphreys and colleagues studied laparoscopic renal ischemia time in a 2-kidney porcine model, but histologic analysis did not show any significant differences between experimental groups with 30 to 120 minutes clamping time. ${ }^{19}$ Their findings did not support scaring and atrophy after prolonged vascular occlusion. The authors attributed part of this unexpected observation to the subjective nature of their pathology scoring system.

The presence of a contralateral nonischemic kidney may have a confounding effect on the observed response to, and recovery from, renal ischemia. ${ }^{11}$ Some experimental work suggested greater resistance to ischemic damage in the solitary kidney. ${ }^{20,21}$ Other studies did not demonstrate this protective effect. ${ }^{22,23}$ We decided to use the contralateral kidney as an individual control for each pig. For financial and ethical issues, we did not use more pigs for the control group (clamp time: 0 minute) and did not replace the deceased pig in the open surgery group.

The originality of our study is the presence of the contralateral kidney as a control group revealing that at a prolonged pneumoperitoneum for up to 3 hours is well-tolerated by a normal unclamped kidney. On histopathology, the right kidneys were completely normal. The left kidneys did exhibit subacute multifocal interstitial nephritis 2 weeks post-unclamping for 5 to 60 minutes WIT in both groups. Irreversible renal damages were noted in the 180-minute 
WIT laparoscopic group. After unclamping, all left renal arteries showed good pulsations prior to the end of the surgery. We also checked prior to surgery all bulldogs clamps and racheted Laparoscopic Marylands.

If renal tolerance to WIT is increased to 60 minutes, these findings will have significant implications for performing laparoscopic partial nephrectomies. However, we did not perform a partial nephrectomy in our study. Therefore, we must mention that renal injuries following a partial nephrectomy and subsequent inflammatory reaction might affect functional outcomes or potentially worsen the injury to the renal unit undergoing WIT.

\section{Conclusion}

Our data suggest that WIT up to 60 minutes results in subacute renal lesions in both open and laparoscopic surgery in a 2-kidney porcine model. Laparoscopic surgery does not confer increased tolerance to renal warm ischemia compared with open surgery for WIT up to 60 minutes as demonstrated by previous studies. Prolonged pneumoperitoneum does not cause any histological renal lesions to unclamped kidneys.

Additional studies are required to confirm whether the human kidney will show similar recovery from long periods of ischemia.

${ }^{\star}$ Department of Urology, Sherbrooke University, Sherbrooke, QC; † Department of Urology, McMaster University, St. Joseph's Hospital, Hamilton, ON; ${ }^{ \pm}$Central Animal Facility, Department of Veterinary Research Pathology, McMaster University, Hamilton, ON

Competing interests: None declared.

Acknowledgements: This study was realized by the grant support of the Surgical Associates, grant number 8-40735. We also thank Tania Fayad, Ph D for critical reading of this article and Dr. Alexandre Douiek for his pathology expertise.

This paper has been peer-reviewed.

\section{References}

1. Novick AC. Surgery of the kidney. In: Walsh PC, Retik AB, Vaughan Jr ED, Wein AJ, editors. Campbell's Urolo gy Vol 4. 8th edition. Philadelphia, PA: Saunders; 2002:3570-643.

2. Novick AC. Renal hypothermia: In vivo and ex vivo. Urol Clin North Am 1983; 10:637-44.

3. Wahlberg E, Dimuzio PJ, Stoney RJ. Aortic clamping during elective operations for infrarenal disease: The influence of clamping time on renal function. J Vasc Surg 2002;36:13-8.

4. Gill IS, Desai MM, Kaouk JH, et al. Laparoscopic partial nephrectomy for renal tumor: Duplicating open surgical techniques. J Urol 2002;167:469-76.

5. Kim FJ, Rha KH, Hernandez F, et al. Laparoscopic radical versus partial nephrectomy: Assessment of complications. J Urol 2003;170:408-11.

6. Orvieto MA, Tolhurst SR, Chuang MS, et al. Defining maximal renal tolerance to warm ischemia in porcine laparoscopic and open surgery model. Urology 2005;66:1111-5.

7. Toosy N, McMorris EL, Grace PA, et al. Ischaemic preconditioning protects the rat kidney from reperfusion iniury. BJU Int 1999;84:489-94.

8. Yilmaz $\mathrm{S}$, Koken T, Tokyol C, et al. Can preconditioning reduce laparoscopy-induced tissue injury? Surg Endosc 2003; 17:819-24.

9. London $\mathrm{ET}, \mathrm{Ho} \mathrm{HS}$, Neuhaus $\mathrm{AM}$, et al. Effect of intravascular volume expansion on renal function during prolonged C02 pneumoperitoneum. Ann Surg 2000;231:195-201.

10. Laven $B A$, Orvieto MA, Chuang MS, et al. Renal tolerance to prolonged warm ischemia time in a laparoscopic versus open surgery porcine model. J Urol 2004;172:2471-4.

11. Baldwin DD, Maynes $\mathrm{L}$, Berger $\mathrm{KA}$, et al. Laparoscopic warm renal ischemia in the solitary porcine kidney model. Urology 2004;64:592-7.

12. Nicholson ML, Metcalfe MS, White SA, et al. A comparison of the results of renal transplantation from non-heart-beating, conventional cadaveric, and living donors. Kidney Int 2000;58:2585-91. Erratum in: Kidney Int 2001;59:821.

13. Kootstra $G$, Wiinen $R$, van Hooff JP, et al. Twenty percent more kidneys through a non-heart beating program. Transplant Proc 1991;23:910-1.

14. Campbell $S C$, Novick AC, Streem SB, et al. Complications of nephron sparing surgery for renal tumors. J Urol 1994;151:1177-80.

15. Haisch C, Green E, Brasile L. Predictors of graft outcome in warm ischemically damaged organs. Transplant Proc 1997;29:3424-5.

16. Glauser EM. Advantages of piglets as experimental animals in pediatric research. Exp Med Surg 1966:24:181-90.

17. Terris JM. Swine as a model in renal physiology and nephrology: An overview. In: Swine in Biomedical Research Vol 1. New York, NY: Tumbleson; 1986:1673-89.

18. Ferwana OS, Pirie SC, Potts DJ. Unilateral renal ischaemia in the rat: Effect of contralateral nephrectomy and intrarenal flush with phosphate-buffered sucrose. Clin Sci (Colch) 1988;74:261-8.

19. Humphreys MR, Castle EP, Lohse CM, et al. Renal ischemia time in laparoscopic surgery: An experimental study in a porcine model. Int J Urol 2009;16:105-9.

20. Fried TA, Hishida A, Barnes IL, et al. Ischemic acute renal failure in the rat: Protective effect of uninephrectomy. Am J Physiol 1984;247:F568-74.

21. Jablonski $P$, Howden $B$, Rae D, et al. The influence of the contralateral kidney upon recovery from unilateral warm renal ischemia. Pathology 1985;17:623-7.

22. Azuma $\mathrm{H}$, Nadeau $\mathrm{K}$, Takada $\mathrm{M}$, et al. Cellular and molecular predictors of chronic renal dysfunction after initial ischemia/reperfusion injury of a single kidney. Transplantation 1997;64:190-7.

23. Ferwana OS, Pirie SC. Unilateral renal ischaemia in the rat: Effect of method of occlusion of the blood supply on function of ipsilateral and contralateral kidneys. Clin Sci (Colch) 1987;73:11-7.

Correspondence: Dr. Robert Sabbagh, Assistant Professor, Sherbrooke University, 3001, 12e avenue Nord, Sherbrooke, QC JIH 5N4; robert.sabbagh@usherbrooke.ca 